International Journal of Current Advanced Research

ISSN: O: 2319-6475, ISSN: P: 2319 - 6505, Impact Factor: SJIF: 5.995

Available Online at www.journalijcar.org

Volume 6; Issue 5; May 2017; Page No. 3989-3992

DOI: http://dx.doi.org/10.24327/ijcar.2017.3992.0413

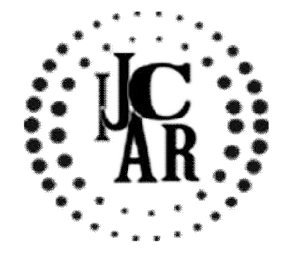

CASE REPORT

\title{
GIANT ENDOMETRIAL POLYP PROTRUDING FROM THE EXTERNAL CERVICAL OS-A CASE REPORT
}

\author{
Stuti Tyagi ${ }^{1}$., Rahul Manchanda ${ }^{2}$., Sudhir Kulkarni ${ }^{3}$ and Madhujeet Gupta ${ }^{4}$ \\ ${ }^{1}$ Fellow in Gynecology Endoscopy, Gynecology Endoscopy Unit, PSRI Hospital, New Delhi \\ ${ }^{2}$ Gynecology Endoscopy Unit, PSRI Hospital, New Delhi \\ ${ }^{3}$ Department of Pathology, PSRI Hospital, New Delhi \\ ${ }^{4}$ Department of Anaesthesia, PSRI Hospital, New Delhi
}

\begin{abstract}
A R T I C L E I N F O
\section{Article History:}

Received $17^{\text {th }}$ February, 2017

Received in revised form $29^{\text {th }}$ March, 2017

Accepted $23^{\text {rd }}$ April, 2017

Published online $28^{\text {th }}$ May, 2017

\section{Key words:}

Endometrial Polyp, Giant Polyp

A B S T R A C T

Endometrial polyps are localized overgrowth of endometrial glands and stroma through the uterine cavity, that are commonly associated with postmenopausal bleeding, infertility and menorrhagia. Several cases have been described in the literature that usually develops secondary to tamoxifen use or by unbalanced estrogen therapy. The polyps commonly do not extend from the external cervical os, and can mimic endocervical polyp or cervical neoplasia if seen protruding. Although the giant polyps which originate from the uterine cavity and protruding from the cervical os are rare entity, we report the case of a gaint endometrial polyp which was protruding from the external cervical os and that developed spontaneously without tamoxifen use in a multiparous 49 year-old woman presenting with heavy vaginal bleeding. Hysteroscopic polypectomy was performed and patient was relieved of her menorrhagia. Diagnosis, management and outcome of this rare entity have been discussed according to the literature.
\end{abstract}

Copyright $(2017$ Stuti Tyagi et al. This is an open access article distributed under the Creative Commons Attribution License, which permits unrestricted use, distribution, and reproduction in any medium, provided the original work is properly cited.

\section{INTRODUCTION}

Endometrial polyps are localized overgrowths of endometrial tissue composed of variable amount of glands, stroma, and blood vessels covered by epithelium. Endometrial polyps commonly presents as vaginal bleeding in pre- and postmenopausal women [1]. The most common size is less than $2 \mathrm{~cm}$, however, polyps greater than $4 \mathrm{~cm}$ are called giant polyps [2]. Endometrial polyps are most frequently seen in multiparous women and there removal is generally performed by hysteroscopic polypectomy [2, 3]. Giant polyps usually occur secondary to high estrogen levels or tamoxifen therapy after breast cancer [4, 5]. Polyps originating from the endocervix are called endocervical polyps [2]. Although giant endometrial polyps, which fill the endometrial cavity, or protruding endocervical polyps with a size greater than $4 \mathrm{~cm}$ are published in several cases, endometrial giant polyp rising to the cervix are very rare[5]. In this case report, we describe the case of a giant $9 \times 5 \times 3 \mathrm{~cm}$ endometrial polyp originating from the anterior wall of the uterine cavity that extended to the external cervical os and protruded into the vagina. The clinical, radiological, hysteroscopic and histopathologic data of this entity have been discussed according to the literature.

\section{Case Report}

A 48-year-old woman, para 4, presented to our hospital with

*Corresponding author: Stuti Tyagi

Fellow in Gynecology Endoscopy, Gynecology Endoscopy

Unit, PSRI Hospital, New Delhi abnormal vaginal bleeding. The patient described heavy vaginal bleeding during menses alongwith intermenstrual bleeding. On clinical examination, a painless mass was palpated intra vaginally. On vaginal speculm examination, a vascularized, hemorrhagic mass protruding from the external cervical os was seen. Transvaginal sonography revealed endometrial thicknesses of $18 \mathrm{~mm}$, which did not correlate with patient's menstrual cycle. The clinical findings and transvaginal sonographic examination suggested an endometrial or cervical growth or carcinoma. Patient was planned for hysteroscopic guided biopsy.

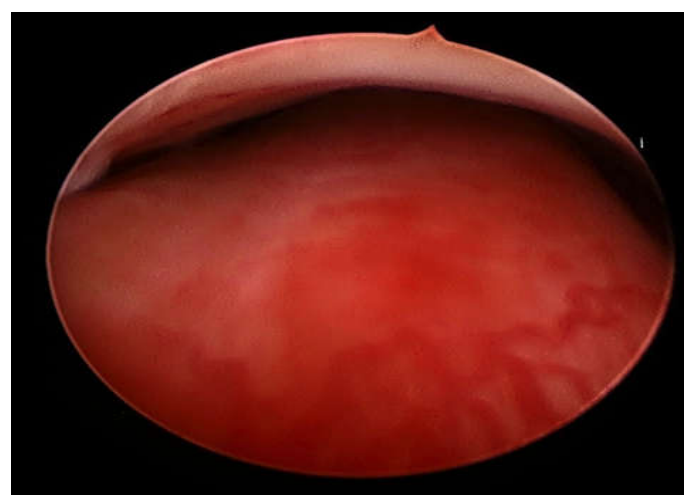

Fig 1 Hysteroscopic examination showed a mass originating from the anterior wall of uterine cavity that extended to the external cervical os and protruded into the vagina. 
Hysteroscopy was performed with $2.9 \mathrm{~mm}$ office hysteroscope (Karl Storz, Tuttingen, Germany). The uterine cavity was distended with normal saline with a pressure of 80 $\mathrm{mmHg}$. On hysteroscopy, in cervical canal polyp was seen. With difficulty uterine cavity was entered. In the uterine cavity, there was hyperplastic endometrium with large polyp of size $9 \mathrm{~cm}$ arising from the anterior wall of uterus on right side, extending to the external cervical os. [Fig-1].

Polypectomy was done with the help of scissors and obtained tissue was sent for histopathological evaluation [fig 2].

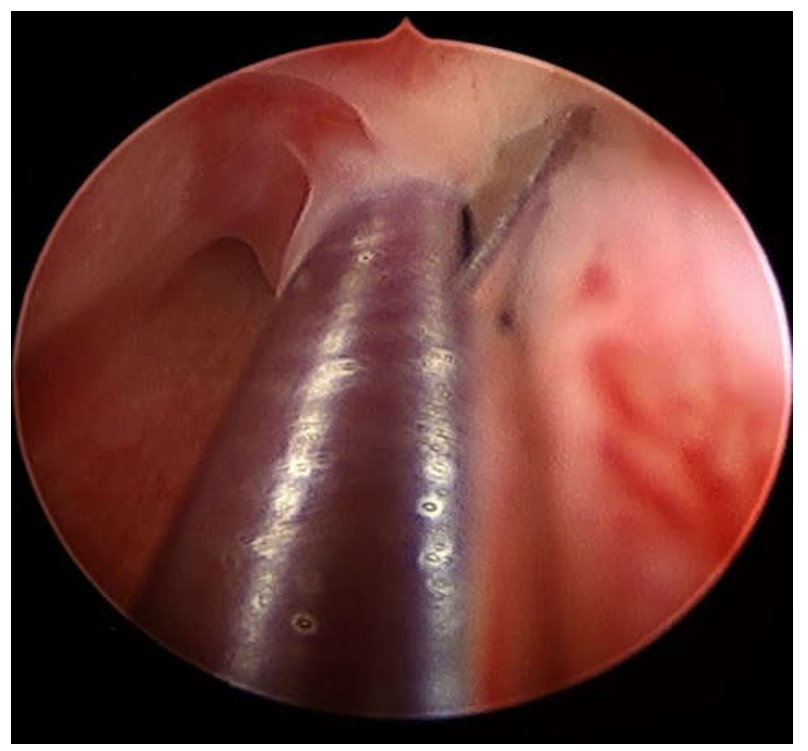

Fig 2 Hysteroscopic view showing polyp being cut with help of scissors.

After removal of the polyp, the uterine cavity was normal. No bleeding was noted from the base of the polyp [fig 3]. The patient was discharged after 6 hours of surgery. The postoperative interval was unremarkable and the patient did not have any complaints on follow up.

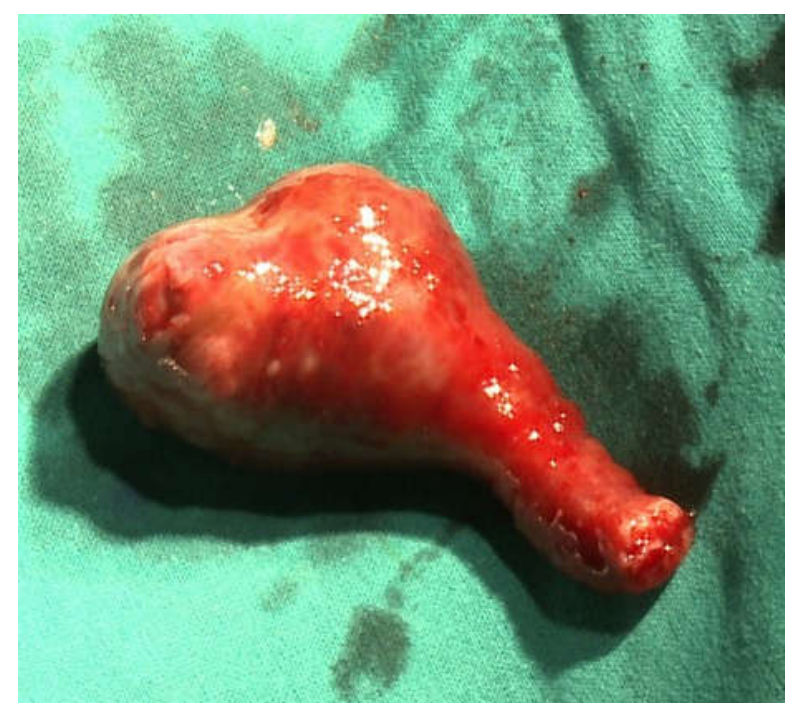

Fig 3 Macroscopic appearance of the giant polyp measuring 9x2.5x3 cm

The pathological diagnosis confirmed it to be a giant endometrial polyp with a size of $9 \times 2.5 \times 3 \mathrm{~cm}$ [Fig-4].

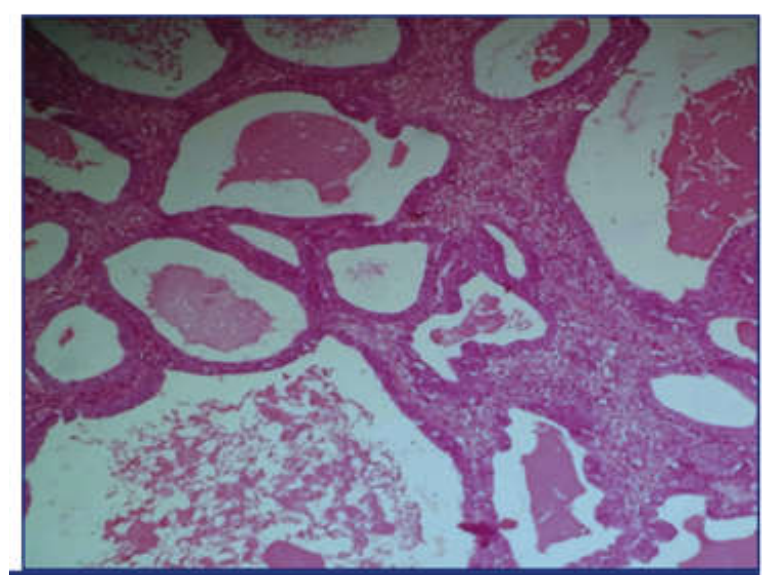

Fig 4 Microscopically, glands of various sizes and irregular shapes are seen with cystic dilatation \& epithelium

Microscopic, report showed widely spaced cystic endometrial glands lined by metaplastic ciliated columnar epithelium.the stroma showed intersitial hemorrhage and scattered lymphocyctes. No nuclear or cytological atypia were noted. No sign of dysplasia or neoplasia was observed in the glandular or metaplastic epithelium. Patient maintained follow up and was relieved of her menorrhagia in concesutive cycles.

\section{DISCUSSION}

Endometrial polyps are localized overgrowths of endometrial tissue composed of variable amount of glands, stroma and blood vessels covered by epithelium. The stroma of the polyp is composed of fibroblast like spindle cells and large blood vessels with thick walls. The polyp epithelium may be active, pseudostratified and after menopause it can be inactive and flat. Depending on response to ovarian hormones, endometrial polyps are divided into three groups viz., mature functioning polyps, immature non functioning polyps and non functioning adenomyomatous polyps [2].

The development of endometrial polyps has been explained by number of molecular mechanisms such as monoclonal endometrial hyperplasia, over-expression of endometrial aromatase and gene mutations. Polyps have characteristic cytogenetic rearrangements similar to uterine leiomyoma. Rearrangements in the High-Mobility Group (HMG) family of transcription factors seem to play a role in pathogenesis [6]. Indraccolo $\mathrm{U}$ et al., studied the pathogenesis of endometrial polyps and they demonstrated a causative link: ageing, bcl-2 expression, obesity, tamoxifen regardless of timing and unbal anced oestrogen therapy [7].

Endometrial polyps are most frequently seen in multiparous women in the fifth decade. They are common cause of vaginal bleeding in pre and postmenopausal women, affecting $25 \%$ of them $[8,9]$. They are also associated with infertility. Some may be asymptomatic. In postmenopausal women, polyps usually present with bleeding or discharge accounting for $24.3 \%$

The most common size of polyp is less than $2 \mathrm{~cm}$, and those greater than $4 \mathrm{~cm}$ are called giant polyps. Giant endometrial polyps occur with increased frequency secondary to unbalanced oestrogen levels or tamoxifen exposure after breast cancer [2]. 
The prevalence of malignancy with endometrial polyps is $1-$ $3 \%$ [10]. The risk factors of malignancy within polyps are ageing, obesity, arterial hypertension, postmenopausal period, and tamoxifen.

Hormonal factors may be involved as indicated by endometrial abnormalities in patients treated with tamoxifen. Despite being an oestrogen antagonist, tamoxifen has oestrogen agonistic effects on the endometrium. The partial agonistic activity of tamoxifen in postmenopausal women may produce a hormonal environment of low levels of unopposed oestrogen similar to that in perimenopausal woman. In our patient, the polyp was asymptomatic and developed spontaneously as the patient was not on tamoxifen or other drugs including hormone replacement treatment.

In the literature, most giant polyps protruding from the external cervical os originated from the cervix and are called endocervical polyps. Other giant polyps which originate from the endometrium but are contained within the uterine cavity are called endometrial polys. Interestingly in our case report, the polyp originated in the uterine cavity, extended into the cervix and protruded into the external cervical os.

Non-invasive techniques such as transvaginal ultrasonography, with or without the use of $3 \mathrm{D}$ ultrasonography and contrast techniques, are considered as the first line for diagnosis. Transvaginal ultrasonography is a routine, non invasive component of investigation. However, with advent of hysteroscopy it has now become choice for diagnosis as well as treatment at the same sitting. On the sonographic examination, $18 \mathrm{~mm}$ thick endometrium was seen in our case which was suspicious of polyp but could not be confirmed. It was on hysteroscopy, that the diagnosis of endometrial polyp was confirmed.

Histopathological examination must be performed on all resected polyps to rule out endometrial polyps $(0.5 \%-3 \%)$ with malignant foci [2]. Lasmar BP et al., reported that endometrial polyps larger than $15 \mathrm{~mm}$ are associated with hyperplasia [9] and Wang $\mathrm{J}$ et al., identified that polyps measuring more than $10 \mathrm{~mm}$ are associated with malignancy [11]. For the treatment and histologic diagnosis of endometrial polyps, hysteroscopic resection is the most effective method, while blind biopsy and curettage have low diagnostic accuracy and should not be performed. Table1 shows various giant polyps reported in literature.

\begin{tabular}{ccccc}
\hline Author & Size (cm) & Origin & Tamoxifen treatment $\begin{array}{c}\text { Cervical } \\
\text { protrusion }\end{array}$ \\
\hline Nomikos et al., [4]. & 8 & Uterus & + & - \\
Moon et al., [5] & 7 & Uterus & + & - \\
Cil et al., [10] & 8 & Uterus & - & + \\
Unal et al., [12] & 10 & Uterus & - & + \\
Arıdogan et al., & 14 & Cervix & - & + \\
[13] & 15 & Cervix & - & + \\
Branger et al., [14] & 5 & Cervix & - & + \\
Amesse et al., [15] & 9 & Uterus & - & - \\
Present case & 9 & & & + \\
\hline
\end{tabular}

\section{CONCLUSION}

In summary, the origin and pathogenesis of endometrial polyps have not been fully evaluated and understood. Giant endometrial polyps are rare entities and they are associated with tamoxifen and unbalanced oestrogen levels. For diagnostic and therapeutic management, hysteroscopy is the gold standard whereas blind dilation and curettage is not preferred. Removal for histologic assessment is appropriate in postmenopausal women. In our case report of a gaint endometrial polyp originating in anterior uterine wall that protruded through the cervix neither tamoxifen nor HRT was used. Hysteroscopic examination alongwith histopathological evaluation provide the definitive diagnosis.

\section{Acknowledgement}

I would acknowledge the inspiration and support of my teacher Dr. Rahul Manchanda, my parents Mr. Anil Kumar Tyagi and Mrs. Poonam Tyagi and my husband Dr. Puneet Tyagi. I would like to acknowledge the support provided by our institute Manchanda's Endoscopic Centre, PSRI Hospital, New Delhi,

\section{Reference}

1. Jutras ML, Cowan BD. Abnormal bleeding in the climacteric. Obstet Gynecol Clin North Am. 1990 Jun; 17(2):409-25. PubMed PMID: 2234751.

2. Peterson WF, Novak ER. Endometrial polyps. Obstet Gynecol. 1956 Jul; 8(1):40-9. PubMed PMID: 13335063.

3. Golan A, Ber A, Wolman I, David MP. Cervical polyp: evaluation of current treatment. Gynecol Obstet Invest. 1994; 37(1):56-8. PubMed PMID: 8125411.

4. Nomikos IN, Elemenoglou J, Papatheophanis J. Tamoxifen-induced endometrial polyp. A case report and review of the literature. Eur $J$ Gynaecol Oncol. 1998; 19(5):476-8. PubMed PMID: 9863916

5. Moon SH, Lee SE, Jung IK, Jeong JE, Park WY, Yi WH, Suh DS, Yoon MS, Kim KH. A giant endometrial polyp with tamoxifen therapy in postmenopausal woman. Korean J Obstet Gynecol. 2011; 54(12):836840.

6. Dal Cin P, Timmerman D, Van den Berghe I, Wanschura S, Kazmierczak B, Vergote I, et al. Genomic changes in endometrial polyps associated with tamoxifen show no evidence for its action as an external carcinogen. Cancer Res. 1998; 58:2278.

7. Indraccolo U, Iorio R, Matteo M, Corona G, Greco P, Indraccolo SR. The pathogenesis of endometrial polyps: A systematic semi-quantitative review. Eur $J$ Gynaecol Oncol. 2013; 34(1):5-22.

8. Jutras ML, Cowan BD. Abnormal bleeding in the climacteric. Obstet Gynecol Clin North Am. 1990; 17(2):409-25.

9. Lasmar BP, Lasmar RB. Endometrial polyp size and polyp hyperplasia. Int $J$ Gynaecol Obstet. 2013; 123(3):236-39.

10. Çil AS, Bozkurt M, Kara D, Guler B. Giant endometrial polyp protruding from the external cervical os in a postmenopausal woman: Magnetic resonance imaging and hysteroscopic ndings proceedings in obstetrics and gynecology. 2013; 3(3):2.

11. Wang J, Zhao J, Lin J. Opportunities and risk factors for premalignant and malignant transformation of endometrial polyps: Management strategies. J Minim Invasive Gynecol. 2010; 17(1):53-58.

12. Ünal B, Doğan S, Karaveli FS, Şimşek T, Erdoğan G, Candaner I. Giant endometrial polyp in a postmenopausal woman without hormone/drug use and vaginal bleeding. Case Reports in Obstetrics and Gynaecology. 2014; 2014:518398. 
13. Aridogan N, Cetin MT, Kadayifci O, Atay Y, Bisak U. Giant cervical polyp due to a foreign body in a 'virgin'. Aust N Z J Obstet Gynaecol. 1988; 28(2):146-47.

14. Branger C, Dreher E, Burkhardt A, Schmuckle U. Giant polyp of the cervix. Geburtshilfe Frauenheilkd. 1991; 51(2):148-49.
15. Amesse LS, Taneja A, Broxson E, Pfaff-Amesse T. Protruding giant cervical polyp in a young adolescent with a previous rhabdomyosarcoma. J Pediatr Adolesc Gynecol. 2002; 15(5):271-77.

\section{How to cite this article:}

Stuti Tyagi et al (2017) ' Giant Endometrial Polyp Protruding From The External Cervical Os-A Case Report', International Journal of Current Advanced Research, 06(05), pp. 3989-3992.

DOI: http://dx.doi.org/10.24327/ijcar.2017.3992.0413 